\title{
Segmental absence of intestinal musculature
}

\author{
Shirish Nandedkar • Kamal Malukani • Prasann Bandi • \\ Renu Nayak
}

Published online: 28 February 2014

(C) Indian Society of Gastroenterology 2014

Segmental absence of the intestinal musculature (SAIM) is a rare clinical entity that presents usually in the neonatal period. Our patient was a 3-year-old male who was brought with the complaints of chronic constipation and a 2-day history of nonbilious vomiting, abdominal distension, and fever. He was subjected to exploratory laparotomy and found to have an intestinal perforation. Resection anastomosis of the bowel

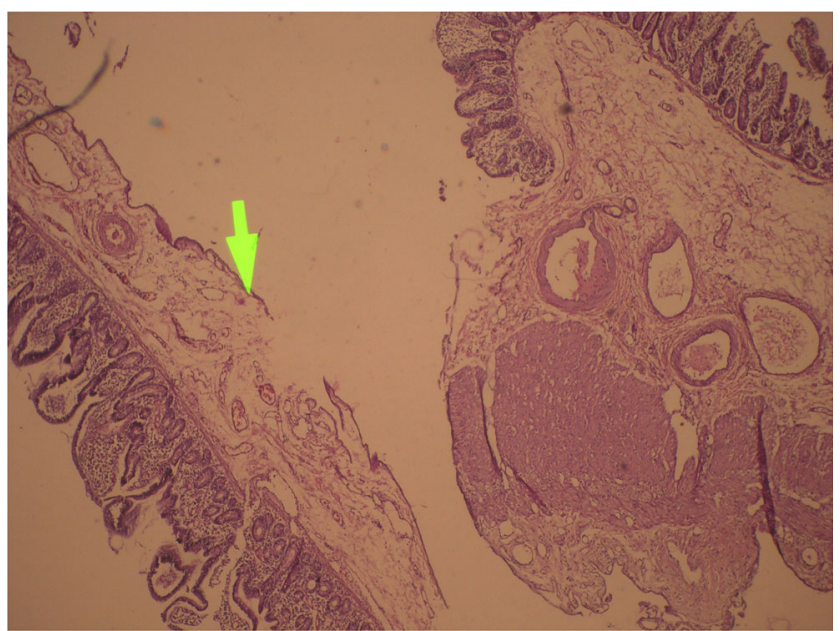

Fig. 1 Microphotograph of small intestine showing an absence of muscularis propria in one section (arrow); other sections are showing hypertrophy of muscularis propria $(\mathrm{H} \& \mathrm{E}, \times 40)$ was done. The surgical pathology specimen consisted of a 30 -cm-long piece of small intestine, with thin bowel wall and one area of healed perforation. Histopathological examination revealed a multifocal partial or complete absence of muscularis propria (Fig. 1). The mucosa and muscularis mucosa appeared unremarkable. The submucosa and serosa were edematous and infiltrated by lymphocytes and plasma cells. Foci of hyperplasia of the muscularis propria were seen. The myenteric plexus was not seen in areas of absence of muscle but present where muscular layer was present. Diagnosis of SAIM is made only after pathologic examination of the resected bowel [1]. The usual presentation is consistent with peritonitis, although obstruction may also be a presentation. SAIM may be either congenital or acquired, the latter possibly secondary to ischemic injury [2].

\section{References}

1. Davis JS, Ryan ML, Shields JM, et al. Segmental absence of intestinal musculature: an increasingly reported pathology. J Pediatr Surg. 2012;47:1566-71.

2. Oretti C, Bussani R, Janes A, Demarini S. Multiple segmental absence of intestinal musculature presenting as spontaneous isolated perforation in an extremely low-birth-weight infant. J Pediatr Surg. 2010;45: E25-7.

S. Nandedkar $\cdot$ K. Malukani $(\bowtie) \cdot$ P. Bandi

Department of Pathology, Sri Aurobindo Institute of Medical

Sciences, Gram Bhanwarasala, Indore 453 111, India

e-mail:kamal.malukani@yahoo.com

R. Nayak

Shri Indore Cloth Market Hospital, Indore, India 